\title{
Growth of fungal strains on coffee industry residues with removal of polyphenolic compounds
}

\author{
Ercília M.S. Machado, Rosa M. Rodriguez-Jasso, José A. Teixeira, Solange I. Mussatto* \\ IBB - Institute for Biotechnology and Bioengineering, Centre of Biological Engineering, University of Minho, Campus de Gualtar, 4710-057 Braga, Portugal
}

\section{A R T I C L E I N F O}

\section{Article history:}

Received 12 February 2011

Received in revised form 1 October 2011

Accepted 14 October 2011

Available online 20 October 2011

\section{Keywords:}

Coffee silverskin

Spent coffee grounds

Solid-state fermentation

Biodegradation

Microbial growth

Phenolic compounds

\begin{abstract}
A B S T R A C T
Coffee silverskin (CS) and spent coffee grounds (SCG) are abundant residues generated by the coffee industry, but up till now they are practically unutilized being discharged to the environment or burned for elimination. In the present study, the ability of seven different fungal strains from the genera Aspergillus, Mucor, Penicillium, and Neurospora, to grow and release phenolic compounds from these residues under solid-state cultivation conditions was evaluated. All the strains were able to growth on CS and SCG, but Penicillium purpurogenum, Neurospora crassa and Mucor were able to release the highest amounts of phenolic compounds from both residues. Phenolic compounds have wide-range applications in the food and pharmaceutical industries, and thus, the extraction of these compounds could be a valuable alternative for the exploitation of CS and SCG. Additionally, the use of solid-state fermentation to obtain these compounds has a positive environmental impact because the use of chemical solvents is avoided.
\end{abstract}

(c) 2011 Elsevier B.V. All rights reserved.

\section{Introduction}

The generation of wastes is inherent in any productive sector. Coffee is the second largest traded commodity in the world after petroleum, and therefore, the coffee industry is responsible for the generation of large amount of residues [1]. Among these residues, silverskin and spent grounds are generated in significant amounts and merit special attention. Coffee silverskin (CS) is a tegument that covers the coffee beans, separated during the roasting process. Spent coffee grounds (SCG) are the solid residues obtained during the treatment of raw coffee powder with hot water or steam to prepare instant coffee. A worldwide annual generation in the order of 6 million tons is estimated for SCG [2].

In some countries, CS has been used as soil fertilizer or as fuel [3], while SCG has been used as fuel in industrial boilers of the same industry, due to its high calorific power of approximately $5000 \mathrm{kcal} \mathrm{kg}^{-1}$ [4]. However, most of these residues remain unutilized, being discharged to the environment or burned for elimination, which are not environmentally friendly techniques. Discharges to the environment cause severe contamination and environmental pollution problems due to their toxic nature $[5,6]$, and burning results in the production of carbon dioxide, the green house gas [2]. Some studies about the composition of CS and

\footnotetext{
* Corresponding author. Tel.: +351 253604 424; fax: +351253604 429 . E-mail addresses: solange@deb.uminho.pt, solangemussatto@hotmail.com (S.I. Mussatto).
}

SCG $[7,8]$ reveal that both residues are rich in phenolic compounds. Furthermore, to be derived from the coffee beans, several of these phenolic compounds may present important biological functions and antioxidant potential, with interest for the food and pharmaceutical industries [9]. Therefore, extraction of phenolic compounds from CS and SCG would open up opportunities for their utilization.

Solid-state fermentation (SSF) is a valuable alternative for the reuse of agricultural and agro-industrial residues, since it can be used for the production and/or extraction of compounds like enzymes, flavors, pigments, organic acids, among others. Additionally, this technique does not require the use of chemical solvents, being more environmentally friendly. SSF is defined as fermentation involving solids in absence (or near absence) of free water; however, the substrate must possess enough moisture to support growth and metabolism of microorganisms. The solid substrates used in SSF are mainly natural products from agricultural crops or agro-industrial residues like bran, husks and bagasse. The structural components of these materials include cellulose, hemicellulose, lignin, starch, pectin and proteins, thus being extremely heterogeneous materials that may be used as carbon, energy and nutrient sources for microbial growth $[10,11]$. Substrate heterogeneity varies with each raw material (the species and the plant tissue). Therefore, each substrate with potential for use in SSF has to be assessed in depth.

The objective of this work was to select fungal strains with potential to grow and release phenolic compounds from CS and SCG, under SSF conditions, aiming to find an alternative for the reuse of these residues. 
Table 1

Radial growth rates, reducing sugars and total phenolic compounds extracted by solid-state fermentation (SSF) of spent coffee grounds (SCG) by different fungal strains.

\begin{tabular}{|c|c|c|c|}
\hline Fungal strain & Radial growth rate $\left(\mathrm{mm} \mathrm{h}^{-1}\right)$ & Reducing sugars ( $\mathrm{mg} \mathrm{g}^{-1} \mathrm{SCG}$ ) & Phenolic compounds ( $\mathrm{mg} \mathrm{g}^{-1} \mathrm{SCG}$ ) \\
\hline Penicillium purpurogenum GH2 & $0.32 \pm 0.04^{\mathrm{a}}$ & $10.06 \pm 0.92^{\mathrm{d}}$ & $7.02 \pm 0.80^{f}$ \\
\hline Aspergillus ustus PSS & $0.45 \pm 0.07^{\mathrm{bc}}$ & $9.58 \pm 0.16^{\mathrm{d}}$ & $5.34 \pm 0.16^{\mathrm{d}}$ \\
\hline Aspergillus niger AA20 & $0.24 \pm 0.03^{\mathrm{a}}$ & $5.04 \pm 0.14^{\mathrm{a}}$ & $2.32 \pm 0.08^{\mathrm{a}}$ \\
\hline Aspergillus niger GH1 & $0.47 \pm 0.08^{c}$ & $6.66 \pm 0.56^{\mathrm{bc}}$ & $3.12 \pm 0.12^{\mathrm{b}}$ \\
\hline Aspergillus niger $\mathrm{PSH}$ & $0.28 \pm 0.06^{\mathrm{a}}$ & $5.10 \pm 0.12^{\mathrm{a}}$ & $4.36 \pm 0.08^{c}$ \\
\hline Mucor sp. $3 \mathrm{P}$ & $0.33 \pm 0.05^{\mathrm{ab}}$ & $5.78 \pm 0.66^{\mathrm{ab}}$ & $5.88 \pm 0.06^{\mathrm{de}}$ \\
\hline Neurospora crassa & $0.73 \pm 0.01^{\mathrm{d}}$ & $7.04 \pm 0.22^{c}$ & $6.50 \pm 0.10^{\mathrm{ef}}$ \\
\hline
\end{tabular}

To each response individually, values with the same letter denote values statistically similar at $95 \%$ confidence level.

\section{Materials and methods}

\subsection{Raw materials}

Coffee silverskin (CS) and spent coffee grounds (SCG) from NovaDelta - Comércio e Indústria de Cafés, Lda (Campo Maior, Portugal) were used in the experiments. The materials were dried at $60{ }^{\circ} \mathrm{C}$ to $10 \%$ moisture content to be stored. To be used in the fermentation assays, CS and SCG were sterilized at $121^{\circ} \mathrm{C}$ for $20 \mathrm{~min}$.

\subsection{Microorganisms and inocula}

Filamentous fungi strains belonging to the Fungal Collection of the University of Minho (MUM, Braga, Portugal) and the Food Research Department (DIA, UAC) from the University of Coahuila (Saltillo, Mexico), were used for screening purposes. The strains included three Aspergillus niger (AA20, GH1, and PSH), one Aspergillus ustus (PSS), one Mucor sp. (3P), one Penicillium purpurogenum (GH2), and one Neurospora crassa (ATCC10337). The strains were grown on potato dextrose agar medium at $30^{\circ} \mathrm{C}$. For the inocula preparation, spores from 7 days sporulated cultures were collected in $0.1 \%(\mathrm{w} / \mathrm{v})$ Tween 80 solution and counted in a Neubauer chamber to be inoculated in the fermentation media.

\subsection{Culture medium and fermentation conditions}

The fermentation medium used for substrate moistening was composed of Czapek Dox mineral salts with the following concentrations $\left(\mathrm{g} \mathrm{l}^{-1}\right.$ ): $\mathrm{KH}_{2} \mathrm{PO}_{4}(1.0), \mathrm{MgSO}_{4}$ (0.5), and $\mathrm{KCl}(0.5)$ ( $\mathrm{pH} \mathrm{5.0)}$. Sterilization of the medium was performed at $121^{\circ} \mathrm{C}$ for $20 \mathrm{~min}$.

SSF assays were carried out in Petri plates $(9 \mathrm{~cm}$ in diameter), containing sterile CS or SCG (2.5 and $9 \mathrm{~g}$, respectively) moistened with Czapek Dox mineral salts to achieve 70\% moisture content. Inoculation was carried out in the center of the plates with a suspension containing around $5 \times 10^{5}$ spores $^{-1}$ substrate. The plates were statically incubated at $30^{\circ} \mathrm{C}$ during 6 days. At the end of fermentation, samples were withdrawn and filtered through Whatman qualitative filter paper No. 1 in order to recover the fermentative media for estimation of reducing sugars and total phenolics. Cultivations and analytical analysis were done in triplicate.

\subsection{Analytical methods}

Mycelia radial growth was kinetically monitored by measurement of the colony diameters every $12 \mathrm{~h}$ using a digital micrometer (Mitutoyo 293-561, Japan). Radial growth values were estimated by linear regression and expressed as $\mathrm{mm} \mathrm{h}^{-1}$. Glucosamine content of biomass was taken as an equivalent value for the biomass amount. Glucosamine, after being released from biomass by hydrolysis, was measured as described by Aidoo et al. [12]. The content of total phenolic compounds in the fermented broth was determined using the Folin-Ciocalteu reagent according to the colorimetric method described by Singleton and Rossi [13]. Total reducing sugars were determined by the dinitrosalicylic acid method [14].

\subsection{Statistical analyses}

Means and standard deviations were calculated, and significant differences were estimated using the Tukey multiple-range test at $p<0.05$. Statgraphics Plus for Windows version 4.1 was the software used for data analysis.

\section{Results and discussion}

\subsection{Cultivation of microorganisms on spent coffee grounds}

All the evaluated strains showed significant mycelia growth on SCG. Visually, among the tested microorganisms, $N$. crassa gave the best radial growth results, with a complete areal expansion in only $84 \mathrm{~h}$ of cultivation. A. ustus PSS invaded also the entire plate, but after $132 \mathrm{~h}$. On the contrary, A. niger AA20 and A. niger PSH showed the lowest radial growth on SCG. Table 1 shows the radial growth rate of each strain, and the statistical significance of the results. It can be observed that some strains presented similar growth rates (not different at 95\% confidence level), such as $A$. niger $\mathrm{GH} 1$ and $A$. ustus PSS (0.47-0.45 $\left.\mathrm{mm} \mathrm{h}^{-1}\right)$, and $P$. purpurogenum $\mathrm{GH} 2$, A. niger AA20 and PSH, and Mucor 3P $\left(0.33-0.24 \mathrm{~mm} \mathrm{~h}^{-1}\right)$. As it was visually observed, the highest growth rate was obtained with $N$. crassa, with values different at 95\% confidence level from all the other microorganisms.

Concomitant to the growth of microorganisms, reducing sugars and phenolic compounds were released to the culture media due to the substrate degradation. P. purpurogenum $\mathrm{GH} 2$ and $A$. ustus PSS released the highest amount of sugars during the SCG degradation, whose values were different $(p<0.05)$ from those obtained with the other strains (Table 1). Otherwise, $P$. purpurogenum GH2 and $N$. crassa promoted the highest phenolic compounds release from this residue. These results are in agreement with a previous study where Penicillium spp. were reported to have great and fast potential to degrade SCG due to their cellulolytic, mannolytic and pectinolytic activities [15].

Despite being a sugar-rich residue [8], there are only few works reporting the use of SCG as substrate for SSF. Leifa et al. [6] observed an increase in the protein content and a decrease in the fiber content after SSF of SCG by Lentinus edodes strains. SCG was also used as compost material for the production of edible mushroom from Flammulina and Pleurotus genera $[5,16]$; and the anaerobic digestion of this coffee residue $\left(3 \mathrm{gl}^{-1} \mathrm{day}^{-1}\right)$ has been reported to achieve $99 \%$ conversion of solids, with gas yields of $0.54 \mathrm{lg}^{-1}$ (56-63\% methane) [17].

\subsection{Cultivation of microorganisms on coffee silverskin}

When compared to the growth visually observed on SCG, fungal growth on CS was not very significant for most of the evaluated strains. A. ustus PSS and A. niger GH1, for example, exhibited the lowest growth on CS. However, the $N$. crassa strain had a similar behavior in both coffee residues, covering totally the CS Petri plate after 104 h of cultivation. $P$. purpurogenum GH2, Mucor sp. 3P and $A$. 
Table 2

Radial growth rates, reducing sugars and total phenolic compounds extracted by solid-state fermentation (SSF) of coffee silverskin (CS) by different fungal strains.

\begin{tabular}{|c|c|c|c|}
\hline Fungal strain & Radial growth rate $\left(\mathrm{mm} \mathrm{h}^{-1}\right)$ & Reducing sugars (mg g ${ }^{-1} \mathrm{CS}$ ) & Phenolic compounds ( $\mathrm{mg} \mathrm{g}^{-1} \mathrm{CS}$ ) \\
\hline Penicillium purpurogenum GH2 & $0.33 \pm 0.01^{\mathrm{d}}$ & $4.44 \pm 1.44^{\mathrm{a}}$ & $3.47 \pm 0.24^{\mathrm{d}}$ \\
\hline Aspergillus ustus PSS & $0.13 \pm 0.00^{\mathrm{ab}}$ & $8.15 \pm 3.48^{\mathrm{a}}$ & $2.33 \pm 0.15^{\mathrm{a}}$ \\
\hline Aspergillus niger AA20 & $0.18 \pm 0.01^{\mathrm{bc}}$ & $5.61 \pm 2.48^{\mathrm{a}}$ & $3.33 \pm 0.12^{\mathrm{cd}}$ \\
\hline Aspergillus niger GH1 & $0.12 \pm 0.01^{\mathrm{a}}$ & $6.19 \pm 0.74^{\mathrm{a}}$ & $2.31 \pm 0.09^{\mathrm{a}}$ \\
\hline Aspergillus niger $\mathrm{PSH}$ & $0.20 \pm 0.01^{\mathrm{c}}$ & $7.33 \pm 2.08^{\mathrm{a}}$ & $2.55 \pm 0.06^{\mathrm{ab}}$ \\
\hline Mucor sp. 3P & $0.22 \pm 0.01^{\mathrm{c}}$ & $4.42 \pm 1.55^{\mathrm{a}}$ & $2.96 \pm 0.41^{\mathrm{bc}}$ \\
\hline Neurospora crassa & $0.77 \pm 0.05^{\mathrm{e}}$ & $7.93 \pm 0.76^{\mathrm{a}}$ & $2.92 \pm 0.03^{\mathrm{bc}}$ \\
\hline
\end{tabular}

To each response individually, values with the same letter denote values statistically similar at 95\% confidence level.

niger PSH covered totally the plate between 108 and $132 \mathrm{~h}$. Radial growth rates of the fungi on CS are presented in Table 2. This table confirms that $N$. crassa was the fungus with the highest growth rate on CS. In fact, the growth rate of this strain on CS $\left(0.77 \mathrm{~mm} \mathrm{~h}^{-1}\right)$ was similar to that observed on SCG $\left(0.73 \mathrm{~mm} \mathrm{~h}^{-1}\right)$. The remaining fungi only exhibited growth rates around $0.33-0.12 \mathrm{~mm} \mathrm{~h}^{-1}$ when cultivated in CS.

All the microorganisms released reducing sugars from CS; however, the obtained values did not vary significantly $(p<0.05)$ for the strains. On the other hand, the total phenolic compounds were released in the highest amounts by $P$. purpurogenum $\mathrm{GH} 2, A$. niger AA20, Mucor sp. 3P, and N. crassa, with values oscillating from 3.47 to $2.92 \mathrm{mg} \mathrm{g}^{-1} \mathrm{CS}$.

There are few published data about the use of CS as a substrate for SSF. Recently Murthy et al. [18] reported the production of $\alpha$ amylase by $N$. crassa CFR 308 under SSF conditions using CS. Studies in vitro about the prebiotic activity of CS revealed that different bacteria species (anaerobic and aerobic) are also able to use this residue as carbon and nitrogen source [19].

\subsection{Comparative analyses of fungal cultivations on coffee residues}

When comparing the data obtained from each microorganism, it was possible to observe that the strains had a higher growth rate when cultivated on SCG than on CS (Tables 1 and 2), except for the strains of $N$. crassa and P. purpurogenum GH2, which had similar behavior in both residues. However, an analysis of the biomass growth per gram of substrate revealed that the fungal growth was higher on CS than on SCG (Table 3). Probably, the highest compaction of the SCG particles promoted a micro environment with lower aeration so that the growth of the microorganism occurred basically on the material surface, giving thus a higher growth rate when compared to the values observed for CS. On the other hand, since the CS particles are not powder as SCG, they allowed higher air diffusion through the matrix, a condition that favored the growth of the microorganism not only on the material surface, but also between the particles. This would explain the highest biomass

Table 3

Biomass growth during the fungal strain cultivation in spent coffee grounds (SCG) or coffee silverskin (CS), under solid-state fermentation (SSF) conditions.

\begin{tabular}{lll}
\hline \multirow{2}{*}{ Fungal strain } & \multicolumn{2}{l}{ Biomass growth $\left(\mathrm{g} \mathrm{g}^{-1}\right.$ substrate $)$} \\
\cline { 2 - 3 } & SCG & \multicolumn{1}{l}{ CS } \\
\hline Penicillium purpurogenum GH2 & $0.12 \pm 0.02^{\mathrm{ab}}$ & $0.31 \pm 0.03^{\mathrm{a}}$ \\
Aspergillus ustus PSS & $0.10 \pm 0.00^{\mathrm{a}}$ & $0.26 \pm 0.00^{\mathrm{a}}$ \\
Aspergillus niger AA20 & $0.14 \pm 0.01^{\mathrm{b}}$ & $0.34 \pm 0.02^{\mathrm{a}}$ \\
Aspergillus niger GH1 & $0.11 \pm 0.00^{\mathrm{a}}$ & $0.35 \pm 0.03^{\mathrm{a}}$ \\
Aspergillus niger PSH & $0.10 \pm 0.01^{\mathrm{a}}$ & $0.47 \pm 0.07^{\mathrm{b}}$ \\
Mucor sp. 3P & $0.12 \pm 0.01^{\mathrm{ab}}$ & $0.28 \pm 0.02^{\mathrm{a}}$ \\
Neurospora crassa & $0.11 \pm 0.00^{\mathrm{a}}$ & $0.37 \pm 0.02^{\mathrm{ab}}$ \\
\hline
\end{tabular}

To each response individually, values with the same letter denote values statistically similar at $95 \%$ confidence level. growth results on CS than on SCG. A. niger PSH and N. crassa were the strains with the highest growth on CS.

Although the biomass growth was higher on CS than on SCG, in most of the cases the phenolic compounds were released in higher amounts from SCG than from CS (except for A. niger AA20 and GH1). Such a fact may be related to the kind of phenolic compounds present in these materials, which may or not be easily degraded by the fungi. Coffee beans contain elevated content of polyphenols including catechin, epicatechin, chlorogenic acid, protocatechuic acid, ferulic acid, among others [20], which could be present in SCG. In CS, chlorogenic and caffeic acids are the main phenolic compounds present [19].

When cultivated by means of SSF on SCG enriched with potato and dextrose, Pleurotus sajor-caju PL27 was able to degrade $87 \%$ of the tannins after 32 days of cultivation [21]. In the present study, approximately $40 \%$ of the total phenolic compounds present in SCG were extracted after only 6 days of SSF with the fungus $P$. purpurogenum $\mathrm{GH} 2$, being not necessary the use of other substrate for enrichment of the SCG, which can be considered an important advantage.

\section{Conclusions}

P. purpurogenum GH2, N. crassa ATCC10337 and Mucor 3P are fungal strains with great ability to grow and release phenolic compounds from coffee silverskin and spent coffee grounds under SSF conditions. This finding opens up new possibilities for the exploitation of these residues due to the large demand for phenolic compounds in the food and pharmaceutical industries. The identification of the phenolic compounds present in the produced extracts as well as the determination of their biological activities will be the focus of our future studies.

\section{Acknowledgement}

This study was funded by Portuguese National Fund through FCT - Fundação para a Ciência e a Tecnologia (grant SFRH/BPD/38212/2007).

\section{References}

[1] J.V. Nabais, P. Carrot, M.M.L. Ribeiro Carrot, V. Luz, A.L. Ortiz, Influence of preparation conditions in the textural and chemical properties of activated carbons from a novel biomass precursor: the coffee endocarp, Bioresour. Technol. 99 (2008) 7224-7231.

[2] T. Tokimoto, N. Kawasaki, T. Nakamura, J. Akutagawa, S. Tanada, Removal of lead ions in drinking water by coffee grounds as vegetable biomass, J. Colloid Interface Sci. 281 (2005) 56-61.

[3] M. Saenger, E.-U. Hartge, J. Werther, T. Ogada, Z. Siagi, Combustion of coffee husks, Renew. Energy 23 (2001) 103-121.

[4] M.A. Silva, S.A. Nebra, M.J. Machado Silva, C.G. Sanchez, The use of biomass residues in the Brazilian soluble coffee industry, Biomass Bioenergy 14 (1998) 457-467.

[5] L. Fan, A. Pandey, R. Mohan, C.R. Soccol, Use of various coffee industry residues for the cultivation of Pleurotus ostreatus in solid state fermentation, Acta Biotechnol. 20 (2000) 41-52.

[6] F. Leifa, A. Pandey, C.R. Soccol, Solid state cultivation - an efficient method to use toxic agro-industrial residues, J. Basic Microbiol. 40 (2000) 187-197. 
[7] S.I. Mussatto, E.M.S. Machado, S. Martins, J.A. Teixeira, Production, composition, and application of coffee and its industrial residues, Food Bioprocess. Technol. 4 (2011) 661-672.

[8] S.I. Mussatto, L.M. Carneiro, J.P.A. Silva, I.C. Roberto, J.A. Teixeira, A study on chemical constituents and sugars extraction from spent coffee grounds, Carbohydr. Polym. 83 (2011) 368-374.

[9] K. Ramalakshmi, L.J.M. Rao, Y. Takano-Ishikawa, M. Goto, Bioactivities of lowgrade green coffee and spent coffee in different in vitro model systems, Food Chem. 115 (2009) 79-85.

[10] S. Martins, S.I. Mussatto, G. Martínez-Avila, J. Montañez-Saenz, C.N. Aguilar, J.A. Teixeira, Bioactive phenolic compounds: production and extraction by solidstate fermentation. A review, Biotechnol. Adv. 29 (2011) 365-373.

[11] A. Pandey, Solid state fermentation, Biochem. Eng. J. 13 (2003) 81-84.

[12] K.E. Aidoo, R. Hendry, B.J.B. Wood, Estimation of fungal growth in a solid state fermentation system, Eur. J. Appl. Microbiol. Biotechnol. 12 (1981) 6-9.

[13] V.L. Singleton, J.A. Rossi Jr., Colorimetry of total phenolics with phosphomolybdic-phosphotungstic acid reagents, Am. J. Enol. Vitic. 16 (1965) 144-158.
[14] G. Miller, Use of dinitrosalicylic acid reagent for determination of reducing sugar, Anal. Chem. 3 (1959) 426-428

[15] K. Fujii, K. Takeshi, Penicillium strains as dominant degraders in soil for coffee residue, a biological waste unsuitable for fertilization, J. Appl. Microbiol. 103 (2007) 2713-2720.

[16] F. Leifa, A. Pandey, C.R. Soccol, Production of Flammulina velutipes on coffee husk and coffee spent-ground, Braz. Arch. Biol. Technol. 44 (2001) 205-212.

[17] A.G. Lane, Anaerobic digestion of spent coffee grounds, Biomass 3 (1983) 247-268.

[18] P.S. Murthy, M.M. Naidu, P. Srinivas, Production of $\alpha$-amylase under solid-state fermentation utilizing coffee waste, J. Chem. Technol. Biotechnol. 84 (2009) 1246-1249.

[19] R.C. Borrelli, F. Esposito, A. Napolitano, A. Ritieni, V. Fogliano, Characterization of a new potential functional ingredient: coffee silverskin, J. Agric. Food Chem. 52 (2004) 1338-1343.

[20] J.R. Ramirez-Martinez, Phenolic compounds in coffee pulp: quantitative determination by HPLC, J. Sci. Food Agric. 43 (1988) 135-144.

[21] Y.-S. Wong, X. Wang, Degradation of tannins in spent coffee grounds by Pleurotus sajor-caju, World J. Microbiol. Biotechnol. 7 (1991) 573-574. 